Please do not remove this page

RMIT

UNIVERSITY

\title{
A layered structure surface acoustic wave for oxygen sensing
}

Kalantar-Zadeh, Koroush; Li, X; Wlodarski, W; Brennan, F.

https://researchrepository.rmit.edu.au/esploro/outputs/9921858193701341/filesAndLinks?institution=61RMIT_INST\&index=null

Kalantar-Zadeh, K., Li, X., Wlodarski, W., \& Brennan, F. (2000). A layered structure surface acoustic wave for oxygen sensing. Conference on Optoelectronic and Microelectronic Materials and Devices, 202-205. https://researchrepository.rmit.edu.au/discovery/fulldisplay/alma9921858193701341/61RMIT_INST:Resea rchRepository

Repository homepage: https://researchrepository.rmit.edu.au

(c) 2000 IEEE. Personal use of this material is permitted. However, permission to reprint/republish this material for advertising or promotional purposes or for creating new collective works for resale or redistribution to servers or lists, or to reuse any copyrighted component of this work in other works must be obtained from the IEEE.

Downloaded On 2023/04/26 17:34:38 +1000 


\title{
A layered structure surface acoustic wave for oxygen sensing
}

\author{
K. Kalantar-zadeh, Y. X. Li, W. Wlodarski and F. Brennan \\ RMIT University, School of Electrical and Computer Systems Engineering, Victoria 3001, \\ Australia \\ CRC for Micro-Technology, Hawthorn, Victoria 3122, Australia
}

\begin{abstract}
A novel layered structure Surface Acoustic Wave (layered SAW) transducer has been employed for an oxygen sensing application. It is a $\mathrm{SiO}_{2}(0.36 \mu \mathrm{m}) / \mathrm{ST}$-cut quartz crystal transducer. The dominant mode propagating in the transducer is a combination of Rayleigh and Love modes. Such a structure has the advantage of confining acoustic wave energy to the top selective layer, which increases the sensitivity of the device. A $\mathrm{TiO}_{2}$ thin film deposited by the sol-gel process has been used as the oxygen sensitive layer.
\end{abstract}

\section{A. Introduction}

Micro-sensors that use acoustic waves comprise a very versatile class of sensors. Because they are highly sensitive to surface perturbations, they show extensive applications as gas sensors [1]. In recent years, a new class of layered SAW transducers opened a new era in terms of enhancing the sensitivity of acoustic wave sensors in gas media [2],[3]. They show high sensitivity to any sort of boundary condition perturbation caused by adsorption of gas molecules to the selective layer. The present paper uses this advantage to realise an oxygen gas sensing system.

SAW gas sensors are based on the interaction of the gas molecules with a selective film, which is deposited on a piezoelectric substrate. The propagation characteristics of the electro-mechanical wave travelling along the surface of the sensor are dependent on this interaction. Small changes in the conductivity of the selective layer introduce a perturbation in the electromagnetic boundary condition on the surface of the device, which alters the resonant frequency of the system.

The key design issue of the layered SAW delay line sensor is the ability to launch and detect a single mode acoustic wave. The layered SAW transducer has been designed and fabricated to operate as a delay line in a closed loop system to form an oscillator (Fig. 1). The system design consists of two transducers; one as the sensor and the other as the reference.

The measured output signal is the difference between the frequencies of the reference and the sensor delay line oscillators. $\mathrm{TiO}_{2}$ deposited on the surface of the sensor as the sensitive layer, adsorbs oxygen molecules and changes the conductivity of the surface [4]. This alters the electrical boundary conditions on the active area of the sensor. As a consequence the speed of propagation of the acoustic waves is changed. The change in speed is reflected in a shift in the operational frequency of the sensing delay line oscillator, a shift that is proportional to oxygen concentration. 


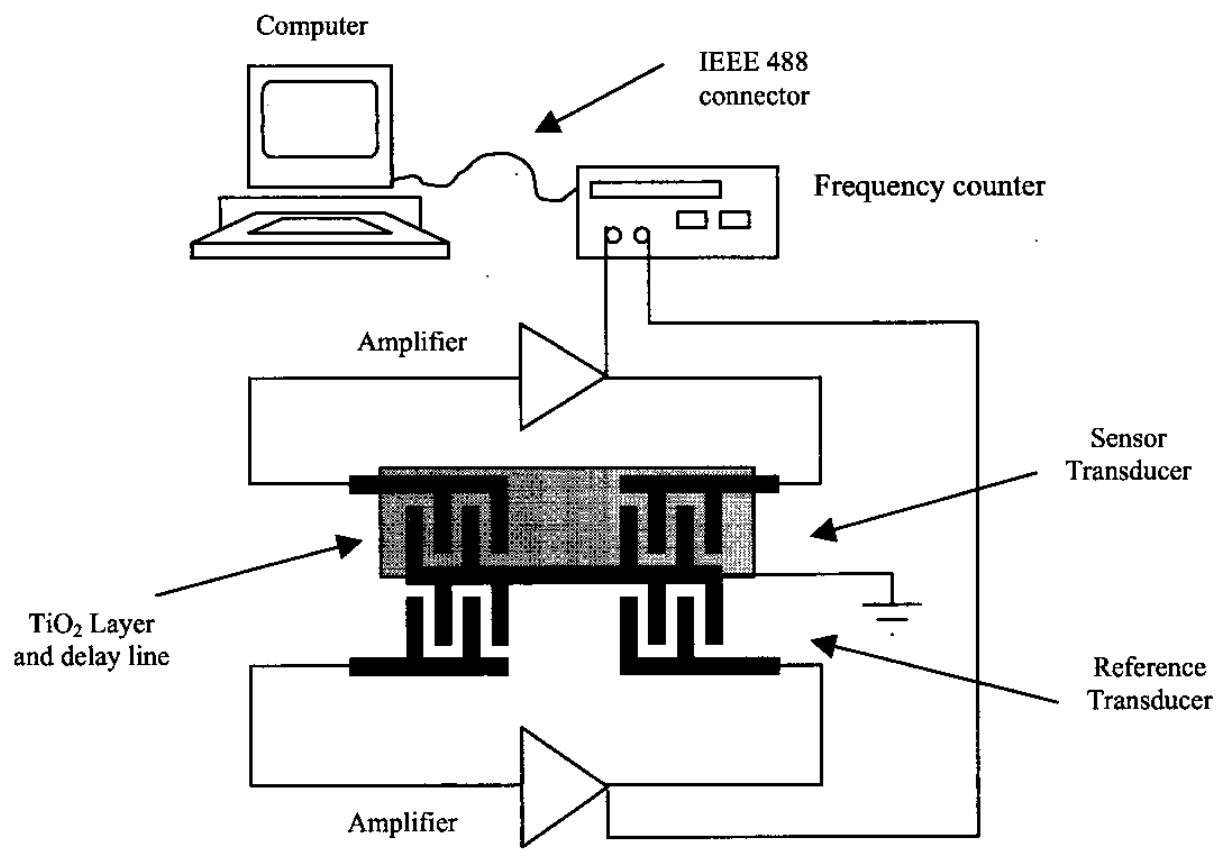

Fig. 1. Overall system set up.

\section{B. Fabrication of the transducer}

The device consists of double line layered SAW transducers. It is fabricated on a $14 \times 19 \mathrm{~mm}^{2}$ and $0.5 \mathrm{~mm}$ thick ST-cut quartz substrate. The transmit and receive interdigital transducers consist of 64 and 16 finger pairs respectively, with the width and separation 12.5 $\mu \mathrm{m}$. The electrode metal layers were deposited by an electron beam evaporation process: $\mathrm{Ti}$ $(200 \AA), \mathrm{Cr}(300 \AA)$ and $\mathrm{Au}(500 \AA)$. The finger-pairs were then patterned using photolithographic techniques. The IDT aperture was $2.5 \mathrm{~mm}$ and the IDT centre to centre length was $4 \mathrm{~mm}$. One transducer was used as a reference and the other has a $\mathrm{TiO}_{2}$ selective layer. The substrate was a ST-cut quartz crystal, which is a piezoelectric with good thermal stability. The IDT patterns were fabricated directly onto the substrate surface. $\mathrm{A} \mathrm{SiO}_{2}$ layer was deposited on the top of the patterned area using an electron beam evaporation technique. The thickness of the $\mathrm{SiO}_{2}$ layer was $3000 \AA$. This layer isolates the sensitive top layer $\left(\mathrm{TiO}_{2}\right.$ is a semiconductor) from the inter-digital transducers (Fig. 2).

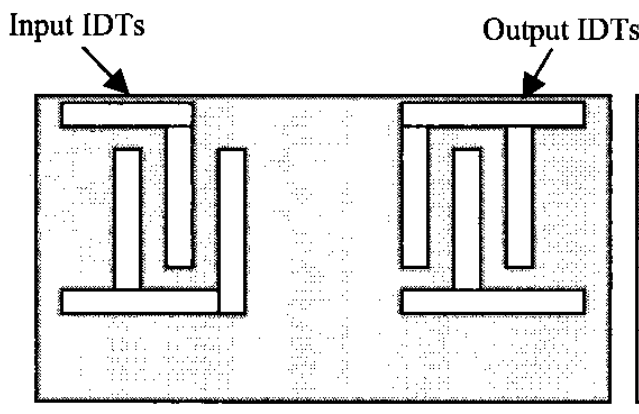

a)

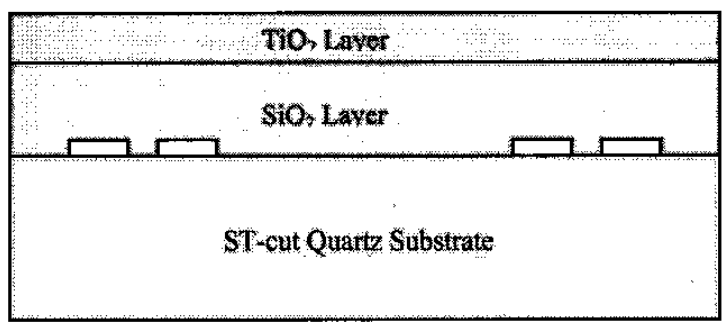

b)

Fig. 2. Layered SAW sensor: a) Top view b) Cross section. 


\section{C. $\mathrm{TiO}_{2}$ sensing layer}

The sol-gel process was employed to prepare a $\mathrm{TiO}_{2}$ thin film on the transducer. The precursor solution was prepared using the starting material of titanium butoxide $\left(\mathrm{Ti}\left(\mathrm{OC}_{4} \mathrm{H}_{9}\right)_{4}\right)$, with a purity of $99 \%$. Analytical purity butanol was used as the solvent. The solution was spun coated $(2500 \mathrm{rpm}, 30 \mathrm{~s})$ on the transducer to form a $\mathrm{TiO}_{2}$ thin film. The film was annealed at $450^{\circ} \mathrm{C}$ for one hour to crystallise.

\section{System set up}

A Keithley 775A dual input frequency counter was used to measure both reference and sensor delay line oscillator frequencies. It was connected to a PC through a GPIB card and an IEEE-488 bus. A virtual instrument media programmed in LabView (National Instrument) software controls the system (Fig. 1).

\section{E. Results and discussions}

Figure 3 shows the frequency response as a function of time when the sensing layer is exposed to different oxygen concentrations. The optimum sensing temperature for measurements was found to be about $320^{\circ} \mathrm{C}$. This temperature was provided by a micro heater fabricated on a sapphire substrate touching the back of the sensor.

The device was mounted inside an enclosed environmental cell. At a temperature of $320^{\circ} \mathrm{C}$ the nominal oscillation frequency was $63.04 \mathrm{MHz}$. All measurements were achieved using a gas flow of 0.1 LPM through the measuring chamber. Fig. 3 shows the frequency response as a function of time. The sensor was exposed to alternate concentrations of oxygen of $100 \mathrm{ppm}, 1000 \mathrm{ppm}$ and $10000 \mathrm{ppm}$ and between each measurement a purging gas of nitrogen was used. Frequency shifts were about $4 \mathrm{kHz}, 16 \mathrm{kHz}$ and $47 \mathrm{kHz}$.

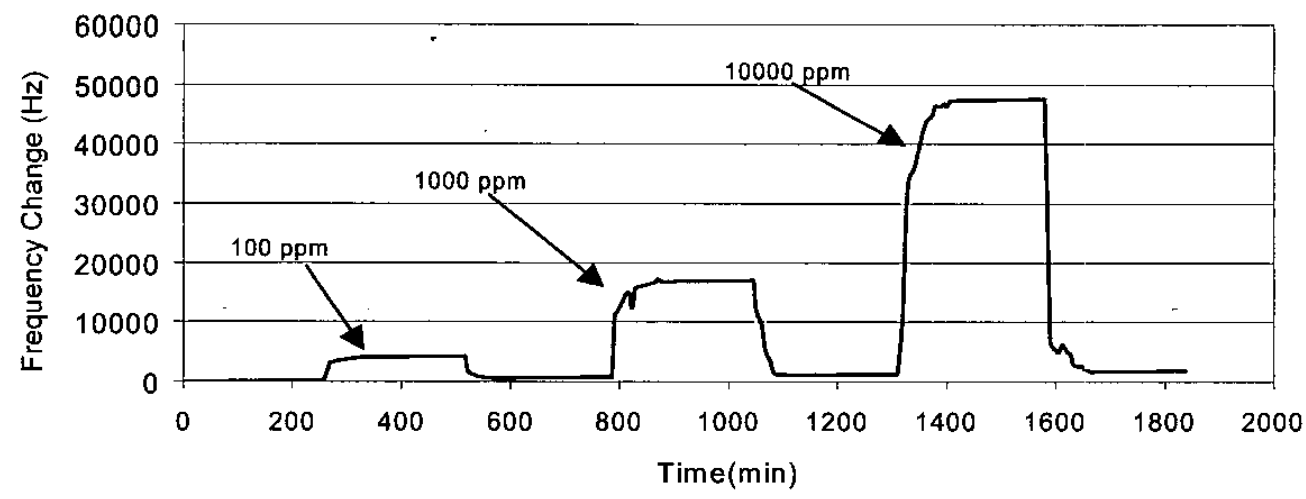

Fig. 3. Frequency response of the system to different oxygen concentrations.

The system shows high sensitivity. The response time for the $63 \%$ of the maximum peak value is about 25 seconds. The electromechanical coupling coefficient, $K^{2}$, for the layered gas sensor was equal to 0.023 . For such a $K^{2}$, the calculated frequency shift [5] for exposure to $100 \mathrm{ppm}, 1000 \mathrm{ppm}$ and $10000 \mathrm{ppm}$ oxygen in nitrogen gas is equal to $3 \mathrm{kHz}$, 
$15 \mathrm{kHz}$ and $45 \mathrm{kHz}$, respectively. The theoretical results are in good agreement with the experimental results.

\section{F. Conclusion}

A system based on layered $\mathrm{SiO}_{2} / \mathrm{ST}$-cut quartz crystal transducers has been successfully fabricated for oxygen sensing. Nanocrystalline $\mathrm{TiO}_{2}$ thin films have been successfully deposited by spin-coating a nano-particle $\mathrm{TiO}_{2}$ suspension. The response to $\mathrm{O}_{2}$ gas was fast and the sensitivity was remarkably high. Frequency shift values obtained from theoretical calculations were in agreement with the experimental results. Further investigations are planned using different $\mathrm{SiO}_{2}$ thicknesses and different materials as the guiding layer.

\section{Acknowledgment}

The authors would like to thank the CRC for Micro-Technology, Australia, for financial support.

\section{References}

[1] J. W. Grate, S. J. Martin and R. M. White, "Acoustic Wave Microsensors, Part II, Analytical Chemistry, vol. 65, No. 21 (1993) pp. 987-995.

[2] M.J. Vellekoop, "Acoustic Wave Sensors and Their Technology", Ultrasonics 36 (1998) pp. 7-14.

[3] B. Jakoby, G. M. Ismail, M.P. Byfield, and M. J. Vellekoop, "A Novel Moleculary Imprinted Thin Film Applied to a Love Wave Gas Sensor," Sensors and Actuators A 76, (1999) pp. 93-97.

[4] M. Z. Atashbar, "Surface Acoustic Wave (SAW) Oxygen Sensors Based on Nanosized $\mathrm{TiO}_{2}$ Thin Film", Doctor of Philosophy Thesis, RMIT University, Melbourne, Australia, (Nov. 1998).

[5] R. Lec, J. F. Vetelino, R. S. Falconer, and Z. Xu, "Macroscopic Theory of Surface Acoustic Wave Gas Microsensors," Proceedings of IEEE Ultrasonics Symp., (1988), pp. 585-589. 